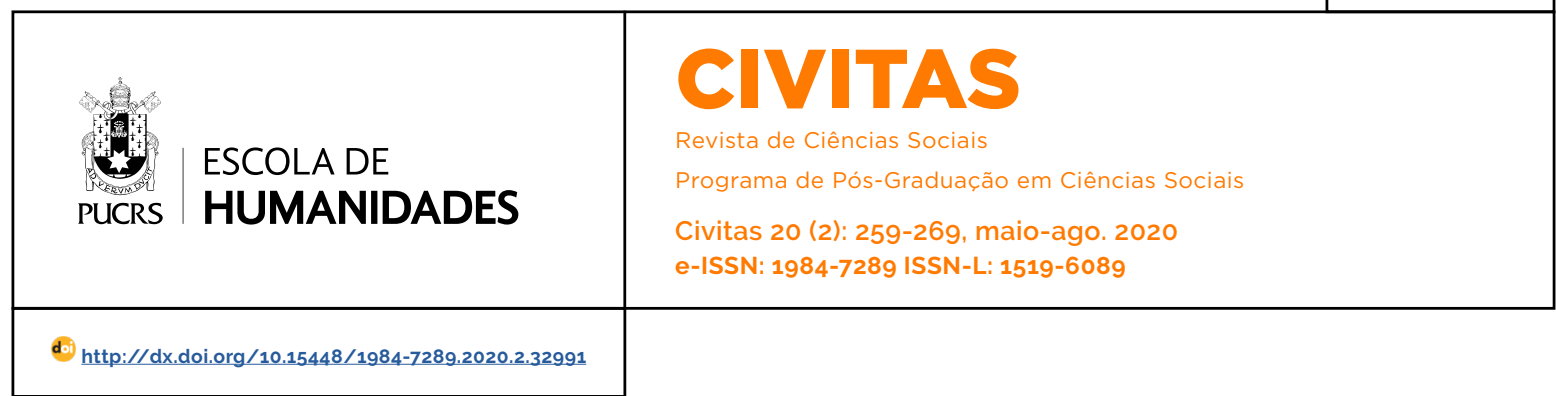

\title{
ARTIGO/ARTICLES
}

\section{Figuras párias em Georg Simmel: a mulher, o pobre, o estrangeiro}

Pariah figures in Georg Simmel: the woman, the poor, the foreigner

Figuras parias en Georg Simmel: la mujer, el pobre, el extranjero

Patrícia da Silva Santos ${ }^{1}$ orcid.org/0000-0002-1266-1311 patricia215@gmail.com

Recebido em: 11 jan. 2019. Aprovado em: 21 ago. 2019. Publicado em: 4 ago. 2020
Resumo: Este artigo tem como objetivo explorar algumas das maneiras como a sociologia desenvolvida por Georg Simmel lida com as assimetrias presentes nas relações de reciprocidade social, tomando como referências as figuras do pobre, da mulher e do estrangeiro. A perspectiva geral é a de que essas três categorias atualizam, cada uma a seu modo, uma oposição onipresente nas discussões simmelianas, a saber: o conflito entre indivíduo e grupo. Nesse sentido, em suas experiências particulares, a mulher, o pobre e o estrangeiro refletem os problemas da rigidez das formas sociais. Por outro lado, em certos casos, é justamente a assimetria constitutiva de suas relações com o grupo que pode ser utilizada em favor de uma renovação das relações sociais por demais enrijecidas pelas formas objetivas da sociedade moderna.

Palavras-chave: Reciprocidade. Simmel. Mulher. Pobre. Estrangeiro.

Abstract: This article presents some of ways that Georg Simmel's sociology deals with the asymmetries found in relationships of social reciprocity, with reference to the figures of the poor individual, the woman and the stranger. The general argument is that each of these three categories relate to an omnipresent opposition in Simmel's discussions, namely: the conflict between the individual and the group. In this sense, in their particular experiences, the woman, the poor individual and the stranger reflect problems associated with the rigidity of social forms. At the same time, the very asymmetry that is constitutive of their relationship with the groups can, in some cases, be used to renew social relations stiffened by the objective forms of modern society.

Keywords: Reciprocity. Simmel. Woman. Poor. Stranger.

Resumen: Este artículo tiene como objetivo explorar modos por los cuales la sociologia de Georg Simmel se ocupa de las asimetrias presentes en las relaciones de reciprocidad social, adoptando como referencias las figuras del pobre, de la mujer y del extranjero. La perspectiva general es que esas tres categorias actualizan, cada una a su modo, un problema omnipresente en las discusiones simmelianas, a saber: el conflicto entre individuo y grupo. En ese sentido, por un lado, la mujer, el pobre y el extranjero reflejan, en sus experiencias particulares, los problemas de la rigidez de las formas sociales. Por el otro, hay situaciones en las cuales esa asimetria constitutiva de sus relaciones con el grupo puede ser utilizada en favor de una renovación de las relaciones sociales, que se encuentran enrigidecidas por las formas objetivas de la sociedad moderna.

Palabras clave: Reciprocidad. Simmel. Mujer. Pobre. Extranjero. 
Quando ultrapassamos o centenário da morte de Georg Simmel (1858-1918), teria ele ainda algo pertinente a nos dizer acerca de figuras tão centrais em nossos debates sociais contemporâneos como a mulher, o pobre e o estrangeiro/estranho? Gostaria de testar a hipótese de que a leitura formal que o autor fez dessas figuras conserva sua atualidade para reflexões acerca de experiências hodiernas. Com esse propósito, inicio retomando alguns pontos fundamentais de seu programa sociológico, para, em seguida, debruçar-me nas discussões especificas acerca de cada uma das figuras. ${ }^{2}$

Como se sabe, no âmbito da sociologia desenvolvida por Georg Simmel a ideia de sociedade como substância fixa é preterida em favor de uma perspectiva movente, que sublinha o seu caráter de "acontecimento" - é nesse sentido que sociedade é "um acontecimento, é a função de receber e efetivar do destino e da configuração de um pelo outro" (Simmel 1999, 70). Em linhas gerais, uma consequência fundamental dessa visada sociológica consiste em praticamente substituir a concepção de sociedade pela de interação: "Toda interação deve ser observada como uma troca: cada conversa, cada amor [...], cada jogo, cada contemplação" (Simmel 2009, 63).

A troca não é de modo algum exclusivamente utilitarista ou econômica. Muito pelo contrário, basta levarmos em consideração a constatação de que "as relações mais finas e firmes vinculam-se frequentemente" ao sentimento de gratidão (Simmel 1992, 664). Antecedendo em alguns anos Marcel Mauss, cujo Ensaio sobre a dádiva foi publicado pela primeira vez em 1925 (Mauss 2017), Simmel afirmava em 1908 que "todos os contatos entre as pessoas se baseiam no esquema de dar e receber o equivalente" (Simmel 1992, 661). Por outro lado, porém, a sociologia simmeliana encontra na disseminação da economia monetária, provavelmente, o seu problema mais central. E, como veremos, tal problema também tangencia boa parte da leitura que Simmel faz a respeito dos tipos sociais, pois, no caso das relações modernas, pautadas cada vez mais no cálculo financeiro, no direito, na intelectualidade e na substituição de meios por fins, os desniveis costumam ser mais acentuados, justamente porque os agentes das trocas não entram em relação como indivíduos autodeterminados, mas de acordo com formas previamente estabelecidas, que se tornam cada vez mais enrijecidas.

Não cabe elaborar extensamente essas dimensões gerais da obra simmeliana. Porém, gostaria de chamar atenção para as consequências do seu "programa sociológico" (Bárbara 2014) para a forma como determinados tipos sociais atuam socialmente. Destarte, nessa compreensão da sociedade como troca constante, há um lugar especial para a reflexão acerca daqueles tipos que entram em relação de maneira proporcionalmente deficitária, ou seja, aqueles que, simultaneamente, pertencem e não pertencem ao grupo social no qual interagem. Há, portanto, espaço para o desenvolvimento de um modo de enxergar os individuos que, por falta de melhor conceito, chamei de "figuras párias". 3 Trata-se de tipos sociais por meio dos quais, como argumenta simmel no caso do estrangeiro/estranho, "momentos que repelem e que distanciam configuram uma forma de estar junto e de unidade interativa" (Simmel 1992, 765).

Grosso modo, de acordo com a assim chamada "sociologia formal" de Georg Simmel seria possivel conceber uma forma para essas interações. Como se fossem padrões de interação que se destacam "dos conteúdos (sentimentos, impulsos etc.) que de certo modo lhes davam vida e passam a operar por própria conta, como receptáculos para relações que se ajustem a eles" (Cohn 1998, 57). Os tipos sociais analisados por Simmel, dentre os quais estão a mulher, o pobre e o estrangeiro/estranho, também fazem parte dessa visada formal acerca da interação social (Vandenberghe 2001, 107).

\footnotetext{
2 Texto inicialmente apresentado na Jornada comemorativa de 100 anos da morte de Georg Simmel: modernidade, interação, capitalismo e cultura, ocorrida em setembro de 2018, na UFPA, Belém.

3 O termo pária tem uma longa e paradoxal história semântica que remonta ao período de expansão marítima europeia e à lógica colonial. De origem indiana, com o significado original de tocador de tambor, a palavra passou a ser utilizada pejorativamente pelos ingleses para se referirem a certos grupos sociais na İndia. Depois, foi assimilada ao vocabulário político ocidental, sempre de maneira ambigua. Interessam-me especialmente suas dimensões de alteridade e assimetria. Para uma reflexão histórica e semântica sobre a palavra pária, conforme Varikas (2010).
} 
Porém, Simmel estava igualmente interessado em tentar captar sociologicamente o momento mesmo da experiência. Nesse sentido, suas análises das relações de reciprocidade destacam momentaneamente tipos sociais de suas múltiplas conexões com o todo (Waizbort 2000, 87), para deterem-se em aspectos singulares. É como se fosse possivel ao pensador ajustar-se a "seus objetos" e "alcançar uma aproximação vital" (Kracauer 2004, 160) para reconstituir o modo como as conformações animicas dos tipos sociais analisados participam das interações sociais. Nesse sentido, a sociologia formal de Simmel revela uma preocupação com o modo como as formas fixas aprisionam as experiências humanas (Cohn 1998). Observados a partir dessa perspectiva, a mulher, o pobre e o estrangeiro entram nas relações de troca social de maneira necessariamente assimétrica. $\dot{E}$ certo que a assimetria é constitutiva das relações de reciprocidade. Porém, no caso específico desses indivíduos, um tipo determinado de assimetria está pressuposto em todas as suas relações com o grupo, conformando-as em moldes próprios e cerceando, por um lado, sua atuação como indivíduos autodeterminados. Porém, em certos casos, é justamente tal assimetria que pode, paradoxalmente, ser utilizada em favor de uma renovação das relações sociais por demais enrijecidas pelas formas objetivas da sociedade moderna.

\section{A mulher}

Na obra de Simmel há uma ampla abordagem a respeito das relações desiguais entre os gêneros, que vem sendo retomada pela fortuna crítica nas últimas décadas (Coser 1977; Lichtblau 1996; Bächi 2003). Não é minha intenção explorar todas as especificidades desse problema do ponto de vista de uma epistemologia feminista contemporânea - embora seja impossivel fugir, aqui e ali, de algumas reflexões críticas. De todo modo, vale destacar que não é possivel medir as contribuições do autor nesse âmbito a partir do conhecimento que as ciências sociais agregaram, especialmente nos últimos anos, a respeito das desigualdades de gênero. Basta lembrarmos que distinções entre sexo e gênero só foram elaboradas por volta dos anos 1970 (Scott 1995) e é ainda mais recente a superação relativa dessa distinção por parte de vertentes do feminismo mais hodierno em favor da percepção enfática de que também o sexo seria efeito de políticas institucionais (Butler 1990). É por isso que, nessa proposta, o que me interessa especialmente no âmbito do debate simmeliano é a posição peculiar da mulher na sociedade moderna e as consequências disso para a maneira como ela entra em relações de reciprocidade.

Há um vínculo muito forte entre as reflexões de Simmel a respeito da modernidade e suas considerações a respeito das mulheres (Lichtblau 1996). Por volta da virada para o século 20, esse pensador argumentava taxativamente que a modernidade contém um "principio masculino" inerente (Simmel 2001): são os homens que formataram a racionalidade moderna, sua divisão do trabalho, seu modo de produção e sua objetividade. De acordo com Simmel, a cultura da humanidade não é "assexuada", ao contrário, "nossa cultura objetiva, com exceção de muitíssimo poucos domínios, é completamente masculina" (Simmel 2001, 252). Além disso, para a sua "realização constantemente repetida", essa cultura requer "forças especificamente masculinas" (Simmel 1985, 161):

[...] a mistura ingênua dos valores masculinos com os valores, propriamente, é sustentada por relações de poder históricas que se expressam logicamente no fatídico duplo sentido do conceito de "objetivo" [Sachliche]: o objetivo aparece como a ideia puramente neutra, na mesma medida sobre as unilateralidades masculino-feminino; mas o "objetivo" é também a forma especial de realizações que corresponde ao modo de ser especificamente masculino (Simmel 2001, 259). ${ }^{4}$

Esse processo que torna absoluto um principio masculino ao objetivá-lo como igualmente válido

\footnotetext{
4 O argumento se repete em outro texto: "As exigências artísticas e as exigências do patriotismo, assim como o cosmopolitismo, a mora geral e as ideais sociais singulares, a justiça do julgamento prático e a objetividade do conhecimento teórico, a força e a profundidade da vida - por certo, todas essas categorias são, de modo geral, igualmente humanas, de acordo com sua forma e pretensão, mas em seu desenvolvimento histórico de fato, elas são completamente masculinas. Se chamamos tais ideias que aparecem como absolutas de puramente objetivas, então, na vida histórica de nosso gênero vale a equação: objetivo = masculino" (Simmel 2001, 224).
} 
para ambos os gêneros fundamenta a relação de dominação dos homens sobre as mulheres por meio de uma estratégia que é típica de toda "dominação que repousa em uma tirania subjetiva". Tal estratégia consiste em: "transformar poder em direito" (Simmel 2001, 225).

Em decorrência do fato de ser fruto do "espírito e do labor dos homens", nossa cultura seria "verdadeiramente adaptada somente à capacidade de produção masculina" (Simmel 1985, 161). E Simmel ainda acrescenta: "a natureza de nosso trabalho cultural, e não só sua quantidade, se dirige especialmente a energias masculinas, a sentimentos masculinos, a uma intelectualidade masculina" (Simmel 2001, 258). Também nesse sentido, a ideia moderna de individuo como um eu altamente diferenciado e encerrado em si mesmo só teria sido desenvolvida plenamente pelos homens.

Simmel chega a afirmar que as mulheres seriam a expressão de uma "unidade pré-diferenciada" (Simmel 1985, 148), por isso, elas estariam mais atreladas ao "tipo genérico" do que os homens. Em alguma medida, em conformidade com essas reflexões, é como se as mulheres não tivessem assimilado a "cultura objetiva" da modernidade, nem do ponto de vista da sua participação social efetiva na esfera pública, nem de uma perspectiva subjetiva, ligada à identidade. Porém, é necessário observar que, nesse passo, o argumento é um tanto ambíguo: apesar de referir-se ao processo histórico de constituição do moderno e seu princípio masculino (aspecto que continua sendo relevante no debate feminista), 5 Simmel por vezes registra suas ideias em termos essencialistas, como se houvesse um "selo puro e autêntico da feminilidade" (Simmel 1985, 161), que dotasse as mulheres de maior "unidade" e as associasse com mais ênfase à natureza.

Disso segue, primeiramente, que, nas mulheres, a medida de gênero e o pessoal podem coincidir. Se as mulheres realmente se associam de modo mais estreito e profundo do que os homens com os obscuros fundamentos originais da natureza, então o que elas têm de mais essencial e pessoal enraiza-se de modo mais forte naquelas funções mais naturais, mais gerais, que garan- tem a unidade da espécie. Além disso, segue também que aquela unidade do sexo feminino distingue de modo menos nítido aquilo que é geral a todos daquilo que cada um tem por si - que cada mulher singular deve refletir em si essa maior unidade do ser (Simmel 2009, 597).

De todo modo, apesar dessa leitura essencialista da mulher, vale mencionar que o pensamento simmeliano foi gradativamente concedendo peso maior às instituições e à cunhagem sócio-histórica das conformações de gênero. Assim, entre a primeira e a segunda versão do texto Weibliche Kultur [cultura feminina], por exemplo, datadas respectivamente de 1902 e 1911, a leitura mais biológica da mulher é amenizada por um destaque maior dado à dimensão social (Bächi 2003).

A despeito desse aspecto um tanto ambiguo, vale frisar um ponto relevante da discussão simmeliana que pode oferecer uma ponte para reflexões mais contemporâneas relativas à desigualdade de gênero. Trata-se da visão da mulher como uma "potencialidade" que não está adequada ao existente, mas que, nem por isso, deixa de exercer efeito sobre ele:

Nesse sentido, portanto, a insuficiência das
mulheres em realizações culturais objetivas
não precisa significar um deficit dinâmico a
uma exigência humana genérica, mas apenas
a inadequação entre um modo de ser, no qual
todos os conteúdos vitais existem apenas a
partir da força de um centro subjetivo indivisí-
vel e fundem-se com este centro de maneira
imediata - e a demonstração de sua eficácia
em um mundo objetivo, tal como ele está
construído através da natureza diferencial do
homem (Simmel 2001, 258).

Para elaborar esse argumento, é importante chamar atenção para a reflexão mais geral de Simmel que está no pano de fundo dessa discussão acerca do gênero. Essa cultura masculina do mundo moderno é a mesma cultura na qual o dinheiro se sobrepõe a tudo, inclusive às relações entre os gêneros - vale lembrar, por exemplo, a discussão a respeito da prostituição (Simmel 1985).

Do ponto de vista do diagnóstico geral do moderno, o que Simmel tem em mente engloba o modo

5 Conferir, por exemplo: Pateman (1993); Benhabib e Cornell (1987); Fraser (2013) e outros. 
como aspectos puramente objetivos associados às trocas monetárias se impuseram nas relações entre os homens, tornando preponderantes trocas que se realizam entre objetos, na mesma medida em que as trocas humanas entram em eclipse:

Na medida em que alguém dá alguma coisa e outro devolve uma coisa que tem o mesmo valor, o caráter anímico das relações entre os homens projeta-se nos objetos e essa coisificação da relação, a sua acomodação às coisas que andam de lá pra cá, é realizada de tal modo que, na economia desenvolvida, aquela interação pessoal recua totalmente e as mercadorias ganham vida própria, que as relações e as equalizações de valor entre elas realizam-se automaticamente, de modo meramente calculista, e os homens aparecem apenas como os executores das tendências ao deslocamento e comparação alocadas nas próprias mercadorias (Simmel 1992, 662).

Quando trata das mulheres, Simmel acentua o fato de que elas são vitimadas por esse diagnóstico em virtude de sua suposta "unidade pré-diferenciada" e, simultaneamente, destaca a sua potencialidade para confrontá-lo. Nesse sentido, o pensador reivindicava que um reequilibrio entre as forças de conteúdos objetivos e subjetivos passaria por uma reorientação da sociedade em direção ao feminino (Lichtblau 1996, 292-314).

Como portadoras de um "outro mundo possivel", as mulheres aparecem aqui como simbolos da pluralidade de identidades subjetivas possíveis - daí a possibilidade de vincular (ainda que com retificações epistemológicas importantes) a argumentação de Simmel a algumas perspectivas mais contemporâneas do debate feminista. Em linguagem contemporânea, poderiamos afirmar que aquilo que Simmel por vezes chamou de "selo puro e autêntico da feminilidade" pode ser pensado justamente como a capacidade de desmoronamento da ideia uniforme de sujeito moderno que foi construida a partir do "principio masculino" reinante.

\section{O pobre}

A discussão sobre o pobre foi publicada inicialmente em 1907 no Archiv für Sozialwissenschaft und Sozialpolitik, sob o título Para a sociologia da pobreza (Zur Soziologie der Armut). Posteriormente, uma versão foi inserida como excurso no livro Soziologie, publicado em 1908, sob o título O pobre. O texto surge em um contexto em que a assistência aos pobres desponta, de maneira ainda incipiente, em diferentes países europeus. Simmel menciona a Inglaterra e a França e se detém na situação alemã. No caso desse último país, o autor menciona o projeto de lei dos pobres de 1842 , que defendia que o estado deveria proteger esse grupo em prol do bem comum (Simmel 1992, 520). ${ }^{6}$

Nesse texto de Simmel não está em jogo somente uma discussão econômica acerca da desigualdade presente na forma como o pobre entra em relação social, mas também uma discussão ética a respeito dos laços sociais. Interessa a Simmel a "oposição fundamental entre as categorias sociológicas e as categorias éticas" (Simmel 1992. 513). Para isso, no início da abordagem, o autor apresenta a perspectiva da sociedade como uma rede de direitos e deveres, na qual o direito é o fato primordial e os deveres são uma "consequência lógica ou técnica" (Simmel 1992, 512). A discussão é feita para introduzir o problema do pobre e sua peculiaridade no âmbito dessa relação formal entre direitos e deveres existente na sociedade.

Para Simmel, o direito do pobre à assistência costuma ser pensado a partir do ponto de vista do dever de assisti-lo. Essa inversão do princípio da reciprocidade social, porém, é problemática. Na medida em que o dever se sobrepõe ao direito na relação entre aqueles que assistem à pobreza e o próprio pobre, os fins dos doadores se sobrepõem aos destes últimos. Na Idade Média, o dever que o cristianismo fez prosperar é aquele de salvar a própria alma ajudando os pobres. Na modernidade, destaca-se a incumbência de

\footnotetext{
6 De acordo com Paugam e Schultheis (1998), na época em que Simmel escreve, a legislação de Bismarck (1883-1889) havia introduzido modificações ao implementar alguns seguros sociais obrigatórios contra velhice, doenças e acidentes de trabalho. Porém, essa segurança era voltada somente para a população trabalhadora, enquanto outros pobres seguiam sendo contemplados apenas pelo assistencialismo. Assim, esse contingente de pessoas não tinha acesso gratuito aos serviços juridicos para reivindicar seu direito (algo que era facultado aos trabalhadores segurados). Na condição de assistidos, eles não possuiam nem mesmo o direito de votar. Esses elementos históricos aparecem em alguma medida na discussão teórica de Simmel, ainda que nem sempre sejam detalhados.
} 
salvar a coletividade. Nos dois casos, o pobre é reduzido à condição de meio.

Por esse sentido da assistência aos pobres torna-se claro que, ao tomar do rico e dar ao pobre, ela não leva de modo algum a uma equalização da posição individual do último, que sua concepção não visa em momento algum suspender a tendência de diferenciação da sociedade entre pobres e ricos. Antes, é a estrutura da sociedade, tal como ela existe agora, que fundamenta tal assistência, à diferença radical de todos os esforços socialistas e comunistas, que desejam suprimir exatamente essa própria estrutura. Seu sentido é precisamente o de aliviar fenômenos de certa maneira extremos de diferenciação social de modo que essa estrutura possa repousar adiante sobre tal diferenciação (Simmel 1992, 518).

Por meio da assistência, a sociedade possibilita ao pobre sua "retomada à atividade econômica" protegendo "sua força corporal da degeneração" e impedindo "impulsos de enriquecimento por violência" (Simmel 1992, 523). Importa salvar a unidade social, não o indivíduo pobre em si mesmo. Não é o pobre com suas necessidades subjetivas que está em jogo, mas a sociedade e sua autoconservação. É por isso que a assistência aos pobres é dotada de um caráter abstrato, "frio", que se distancia de sentimentos e processos que são capazes de fazer o elemento humano sobrepor-se aos objetos - como é o caso da gratidão e da dádiva (Simmel 1992, 661-670). Nesse sentido, Isaac Joseph (2003, 323), comentando a discussão de Simmel, chamará a assistência moderna de "obrigação socializada", ou seja, uma assistência pautada puramente no "bem comum" e ignorante dos interesses particulares daqueles que são assistidos.

Nesse ponto, vale lembrar que o texto sobre o pobre incorpora uma discussão cara a Simmel, referida ao que no discurso sociológico ficou posteriormente conhecido como o "paradigma da dádiva" (Caillé 1988). Em muitas passagens da discussão sobre o pobre, Simmel discorre acerca da ideia de Gabe (dádiva, doação, presente etc.). Embora não seja possivel elaborar uma discussão abrangente sobre o problema, cumpre mencionar que a temática é central no pensamento do autor e configura um contraponto ao avanço das trocas monetárias - precisamente o problema que se coloca como mediador da discussão acerca do pobre. As trocas monetárias significam uma abstração de escopo tão abrangente na sociedade moderna que se realizam de modo puramente objetivo, de tal feita que "a relação dos homens se transformou em relação de objetos" (Simmel 1992, 662). Em uma discussão especifica sobre a gratidão, ao contrário, Simmel a classifica como a "memória moral da humanidade" (Simmel 1992, 662): ela não pode ser reduzida à coerção para retribuir, deve, antes, preservar a liberdade de fazê-lo ou não. Para que ela conserve a dimensão subjetiva do processo de dar e receber, deve ser espontânea. No caso da doação aos pobres, nem há espontaneidade na ação, nem o recebedor é encarado em sua condição de sujeito; ao contrário, ele é eliminado como ser humano, e acentuado como mero meio para fins externos.

Da forma como se organiza a assistência, especialmente na sociedade moderna, é possivel pensar na eliminação jurídica da figura do pobre, na medida em que ele não aparece como fim, mas apenas como meio para a defesa da unidade da sociedade. O importante nesse argumento é que o pobre ocupa um lugar muito assimétrico nessa relação de reciprocidade embutida na assistência. Ele participa, é certo, de uma troca, portanto, de uma sociedade. Mas essa participação específica o exclui como sujeito e o faz existir como mero meio técnico para a conservação do grupo social.

Nesse ponto do texto, Simmel compara o pobre ao estrangeiro/estranho (que, como veremos, é descrito como aquele que está dentro e fora de uma formação social): apesar de fazer parte do grupo, de ser também um cidadão e pertencer à realidade histórica da sociedade em que vive, as políticas de proteção que se direcionam ao pobre não o consideram como um sujeito de direitos, elas apenas levam em conta os deveres da coletividade para com a pobreza. O pobre tem uma participação ambígua na sociedade, que o inclui na medida mesmo em que o exclui:

A exclusão singular que o pobre experimenta por parte da comunidade que o protege é caracteristica para o papel que ele próprio, como um membro situado de maneira particular. ocupa no interior da sociedade; enquanto ele 
é, tecnicamente, mero objeto da sociedade, em sentido sociológico amplo, ele é um sujeito que, por um lado, forma, como todos os outros, a realidade dela, por outro, como todos os outros, está mais além da unidade abstrata e suprapessoal da sociedade (Simmel 1992, 526).

Em discussões contemporâneas sobre inclusão/exclusão, mobilizando um referencial da teoria dos sistemas, Rudolf Stichweh afirma que os excluídos (dentre os quais, figura o pobre) não são levados em consideração como um "endereço de comunicação" - e, como se sabe, a comunicação é elemento central na sociedade funcionalmente diferenciada (Stichweh 2016, 4748). De certo modo, ressalvadas as devidas diferenças, é possivel estabelecer um diálogo entre essa argumentação e a constatação de Simmel de que não é como um indivíduo que o pobre entra na relação de assistência. Nesse sentido, na perspectiva simmeliana, não é possivel haver uma relação individual quando uma das partes é transformada em meio, quando a "unidade coletividade suprapessoal" é aquilo que importa: "Uma tal unidade coletividade suprapessoal pode, com sua teleologia, passar tranquilamente por cima do singular, por assim dizer, sem deter-se nele, para voltar sobre si mesma" (Simmel 1992, 524) - vale mencionar que, nesse argumento, Simmel reproduz um tema central de suas discussões sociológicas que se refere à oposição insuperável entre individuo e sociedade (Waizbort 2000, 118-130).

Gradativamente, o estado tomou para si a assistência à pobreza para torná-la mais objetiva. O direito à assistência que cabe ao pobre circunscreve um minimo necessário à sobrevivência, mas quem determina tal mínimo é o estado. Não se leva em conta fatores subjetivos do pobre para que ele seja estabelecido. Essa dificuldade de participar do grupo como um sujeito é similar àquela que é destacada no caso das mulheres. Aos pobres também é negada a autodeterminação, na medida em que não são eles quem estabelecem as suas próprias necessidades, mas sim a coletividade, por meio da instância do estado. Portanto, é como massa que os pobres são atendidos pelo estado moderno (Simmel 1992, 532), não propriamente como sujeitos de direito.
Com Stichweh $(2016,54)$, poderiamos acrescentar que essa forma de assistência acentua o caráter multidimensional da exclusão de que os pobres são vitimas: afinal, não é só a dimensão econômica que exclui o pobre; a pobreza implica exclusões múltiplas, que a assistência econômica mínima não é capaz de sanar.

Nesse sentido, prossegue Simmel, a assistência - que o pobre, na maior parte das vezes, não tem o direito de reivindicar legalmente - transforma-o em um objeto da "atividade do grupo" e o "coloca a uma distância do todo" (Simmel 1992, 547). O resultado é que, por vezes, ele é visto como um "corpo vil" (corpus vile) que é obrigado a viver às expensas do grupo, por outras, justamente por essa razão, ele converte-se em um inimigo mortal do corpo social.

Na definição de Simmel, o pobre é totalmente determinado por essa relação de assistência uma determinação que, como vimos, é externa a ele, é calculada de maneira "fria" e objetiva pelo estado moderno. A definição usualmente utilizada para o pobre, segundo a qual ele seria aquele cujos recursos não chegam a satisfazer seus fins, é muito fluida e individual para esclarecer essa relação que se estabelece entre ele e o grupo. O pobre, para Simmel, é definido por sua mediação com o grupo.

Como categoria sociológica, o pobre não aparece por meio de uma medida determinada de carência e privação, mas sim como aquele que recebe assistência ou deveria, conforme normas sociais, recebê-la. Nesse sentido, a pobreza não deve ser determinada em si e por si como um estado a ser estabelecido quantitativamente, mas sim somente segundo a reação social que surge em uma situação determinada [...] (Simmel 1992, 551-552).

O mais complicado na situação do pobre do ponto de vista dessa perspectiva de sociedade que se baseia na ideia de reciprocidade é que ele participe do jogo social apenas na condição de pobre, não como indivíduo.

A classe dos pobres, especialmente na sociedade moderna, constitui uma sintese sociológica extremamente peculiar. Em conformidade com seu significado e localização no corpo social, 
ela possui uma grande homogeneidade, que, porém, conforme indicado, carece totalmente das qualificações individuais de seus elementos. [...]. O mais terrivel nessa pobreza [...] é que há homens que, por sua posição social, são apenas pobres e nada mais (Simmel 1992, 554).

Os contemporâneos adeptos do assim chamado "paradigma da dádiva" diriam que, em tal relação, ocorre uma redução simplificadora do homem ao aspecto econômico, à lógica utilitária do mercado (Chanial 2004). Em princípios do século 20, Simmel, atento à forma como o tipo social pobre experiencia as relações modernas, já postulava o cerceamento da sua participação efetiva no esquema de dar e receber o equivalente próprio dos contatos humanos. O que os pobres recebem não corresponde exatamente aos seus interesses particulares - Simmel elabora essa questão no exemplo do presentear: os pobres recebem como presente o que lhes falta, o que precisam ter, não necessariamente o que lhes apraz (Simmel 1992. 550); por outro lado, a eles está interditada a prestação autônoma e autodeterminada.

\section{O estrangeiro/estranho}

Assim como o texto sobre o pobre, o excurso sobre o estrangeiro/estranho consta no Soziologie. Não por acaso, Simmel associa as duas figuras nos dois momentos do livro. Como argumenta Gagnebin (2011, 406), "lido hoje, lesse] texto de Simmel ganha sinistras conotações, tanto mais que a associação entre pobres, 'inimigos interiores', e 'estrangeiros' reforça a predisposição destes grupos ditos 'desviantes' a se transformarem em bodes expiatórios."

Contudo, no caso do estrangeiro/estranho, esse estar, ao mesmo tempo, dentro e fora do grupo possui conotações mais positivas do que aquelas destacadas no caso dos pobres.

O estrangeiro/estranho é pensado como alguém que chega em um lugar e nele permanece. Também aqui é evidenciada a perspectiva de que é a relação social que determina essa figura, mas Simmel acentua, ao lado das observações formais, o momento mesmo da experiência ao elaborar a dinâmica de "liberação" e "fixação" própria dessa condição social específica - as duas palavras paradoxais aparecem na primeira frase do texto e emolduram toda a discussão. Importa a Simmel formular as duas vias da alteridade: como o estrangeiro/estranho é visto pelo grupo e como ele próprio vê o grupo. Vale destacar que a palavra empregada em alemão (Fremde) possui diferentes conotações: não se trata apenas do estrangeiro (aqui poderia ser empregada também a palavra Ausländer), há, além disso, os sentidos de alheio, desconhecido, estranho, todos implicados no adjetivo fremd. O caráter inclassificável é enfatizado, o estrangeiro/estranho não é amigo, nem inimigo, dirá depois Bauman (1999, 61-84). O emprego da palavra Fremde reforça o fato de que as qualidades especificas desse tipo social e o estranhamento nele implicados estão no centro da discussão:

\begin{abstract}
Ele [o estrangeiro/estranho] está fixado dentro de um determinado circulo espacial [...], porém, sua posição nesse circulo é determinada essencialmente pelo fato de que não pertença a ele desde o início, de que porte qualidades que não se originam e nem podem originar-se dele (Simmel 1992, 765).
\end{abstract}

O estrangeiro/estranho aparece como portador de potencialidades, mas também de ameaças, na medida em que introduz qualidades desconhecidas no grupo ao qual adere. Ele estabelece uma relação peculiar de proximidade e distância, afirma Simmel. Trata-se de uma dosagem recorrente e fundamental em Simmel (Waizbort 2000, 138), que também é própria de qualquer tipo de relação social. De todo modo, no caso do estrangeiro/estranho, ela adquire uma pertinência, constância e ambiguidade bastante demarcadas: por estar em um grupo ao qual não pertence desde o início, ele, que está próximo, está distante; ao passo que, justamente por vir de um outro lugar, ele que está distante, está próximo. O estrangeiro/estranho tem uma condição híbrida, na medida em que, ao mesmo tempo, pertence e não pertence: "é um elemento do próprio grupo, de modo não distinto dos pobres e de inúmeros 'inimigos internos' - um elemento que é imanente ao grupo e seu membro, ao mesmo tempo, engloba um estar fora e uma confrontação" (Simmel 1992, 765). 
No decorrer do texto, há uma caracterização sociológica que liga o estrangeiro/estranho ao comércio. Isso porque o comércio é capaz de absorver mais pessoas que outras áreas, assim, pode também incorporar esses individuos que "se intrometem em um circulo como uma peça extra" (Simmel 1992, 766), formula Simmel. Alguém que, portanto, perturba a ordem orgânica do grupo, na medida em que introduz elementos que não estão presentes nele.

Ligada a essa participação no comércio, Simmel menciona a mobilidade como uma característica dos estrangeiros/estranhos. Como não está ligado de modo orgânico ao grupo, ele circula muito mais que os outros. E, por isso, as relações do estrangeiro/estranho são marcadas por uma objetividade maior. É como se eles pudessem observar as relações de uma maneira mais neutra, porque não estão conectados de maneira muito visceral ao grupo.7 Essa objetividade implica também liberdade, porque o estrangeiro/estranho não "está atado a nada pré-estabelecido que pudesse prejudicar sua percepção, seu entendimento, sua ponderação dos dados" (Simmel 1992, 767).

Simmel sustenta que o estrangeiro/estranho indica uma conexão que remete, no limite, à humanidade, à condição de ser humano. Uma vez que estamos ligados a ele apenas por algumas caracteristicas mais gerais, essa ligação mais genérica mesma lembra que somos, no limite. todos seres humanos, a despeito das diferenças individuais (Simmel 1992, 768). Porém, tal lembrança tem também um elemento perturbador porque ela implica desenraizamento e suspensão da identidade - tanto mais porque, como bem elaboraria posteriormente Norbert Elias (1997), unidades mais seculares como a de nação e classe substituíram, ao longo dos séculos 19 e 20, fatores mais religiosos de determinação das identidades e valores sociais.

Por outro lado, contudo, Simmel lembra os problemas que podem surgir quando são acentuadas as diferenças:
Por outro lado, há um tipo de "estrangeirice" que exclui precisamente o que é comum no solo de uma generalidade que engloba as partes; a relação dos gregos com os bárbaros, por exemplo, é típica, também todos os casos nos quais ao outro são recusadas as caracteristicas gerais que são sentidas como própria e puramente humanas. Mas aqui "o estrangeiro/ estranho" não possui nenhum sentido positivo, a relação com ele é não-relação, ele não é levado em consideração como algo que ele é: um membro do próprio grupo. Como tal, ele está ao mesmo tempo próximo e distante, como é o caso da relação fundamentada apenas em uma igualdade humana geral. Entre aqueles elementos [proximidade e distância], porém, surge uma tensão peculiar na medida em que a consciência de ter em comum apenas o que é de fato geral acentua especialmente aquilo que não é comum. No caso de estranhos/ estrangeiros ao país, à cidade, à raça, contudo, esse aspecto não comum também não é algo individual, mas sim uma proveniência estrangeira que é ou poderia ser comum a muitos estrangeiros/estranhos. Por isso, os estrangeiros/estranhos não são percebidos como individuos, mas sim como estrangeiros/ estranhos de um determinado tipo [...] (Simmel 1992, 770, grifo nosso).

Esse ponto interessa especialmente na presente discussão, pois aqui também há a perspectiva de que os estrangeiros/estranhos não são tratados em suas qualidades de indivíduos, mas sob a insígnia geral da estrangeirice, em seu sentido negativo em relação ao que é familiar. 0 exemplo utilizado por Simmel é, não por acaso, o dos judeus da Idade Média (que, à diferença dos cristãos, que pagavam impostos proporcionais às suas fortunas, eram obrigados a pagar valores fixados para judeus em geral). Nesse sentido, em determinadas situações, assim como à mulher e ao pobre, ao estrangeiro/estranho também é negada a individualidade. Quando o que se acentua no estrangeiro/estranho é sua diferença em termos de uma generalidade (de indigenas, venezuelanos, haitianos, judeus, palestinos, sul-americanos etc.), já não são indivíduos autodeterminados que estão em questão, mas sim generalizações que frequentemente acentuam negativamente uma dimensão da diferença

7 Mais tarde, em parte inspirado em Simmel, Schütz $(1994,502)$ irá afirmar que a tarefa primordial do estrangeiro/estranho é precisamente a interpretação. Tarefa tanto mais dificil porque, conforme sua bela formulação para indicar a distância biográfica do estrangeiro/ estranho da história e tradição do grupo aproximado, "túmulos e reminiscências não podem ser transferidos nem conquistados". 
cultural. Onde não vemos sujeitos irmanados a nós sob a perspectiva de serem seres humanos, ressaltamos, frequentemente, os riscos, as ameaças que eles representam para a sobrevivência do grupo ao qual nos identificamos.

\section{Reciprocidade truncada}

Conforme procurei expor em linhas gerais, os três tipos pários aqui retomados das discussões de Simmel estabelecem relações especificas com a sociedade. Todos eles, porém, estão designados sociologicamente por assimetrias negativas nas relações de troca de que participam. Esse ponto especifico me interessa especialmente, pois tais assimetrias provocam entraves para que a mulher, o pobre e o estrangeiro/estranho se apresentem propriamente como individuos em suas relações de reciprocidade: "Uma relação individual pura apenas terá suficiência ética e perfeição sociológica se cada um é para o outro realmente finalidade reciproca - naturalmente, não apenas finalidade" (Simmel 1992, 523-524). Fins de dominação, nos quais está vedada a autodeterminação, não cabem nessa definição, por isso chamei o tipo de relação que se impõe à mulher, ao pobre e a parte dos estrangeiros/ estranhos de reciprocidade truncada.

Nem sempre essa assimetria na interação é negativa. Ela pode carregar a potencialidade para que alterações sejam promovidas no âmbito dos grupos. Especialmente no caso da mulher e do estrangeiro/estranho, esse aspecto é acentuado. Como vimos, a mulher se apresenta, em diferentes textos de Simmel, como aquela que pode reequilibrar o caráter demasiado objetivo do mundo moderno. Ao estrangeiro/estranho, por sua vez, é facultada a capacidade de introduzir elementos novos no grupo do qual se aproxima e de julgar de maneira mais neutra e livre seus desenvolvimentos. No caso do pobre, não há propriamente uma dimensão acentuadamente positiva dessa posição em relação ao grupo, mas sua presença denuncia, inconscientemente, a lógica social moderna da substituição de meios por fins, do enfraquecimento definitivo da relação de dádiva valorizadora do humano em favor do mero cálculo financeiro do custo de preservação da coletividade.

De qualquer forma, o que é geral a essas três categorias de individuos é o fato de que elas expressam, cada uma a sua maneira, uma oposição que Simmel desenvolve como inerente a qualquer conjunto social: aquela existente entre o individuo e o todo. ${ }^{8}$ A ameaça que a mulher, o pobre e o estrangeiro/estranho representam para seus respectivos grupos faz com que a eles seja negada a participação como individualidades. Trata-se de tipos sintomáticos da vida moderna, na qual a economia monetária e suas implicações acentua a assimetria nas relações de reciprocidade.

Ao destrinchar a experiência particular de cada um desses tipos sociais em seus embates com seus respectivos grupos, Simmel fornece visadas específicas para a compreensão do caráter assimétrico da reciprocidade social. Quando a sociologia contemporânea procura as peculiaridades de sujeitos que entram em relação tendo negado "o status de parceiro integral" e sendo impedidos "de participar como um igual na vida social" (Fraser 2013, 176), vale a pena revisitar as proposições feitas por Georg Simmel. Elas indicam, contudo, que dificilmente o ideal do "parceiro integral" é realizável em um mundo no qual "a interação pessoal recua totalmente e as mercadorias ganham vida própria" (Simmel 1992, 662).

\section{Referências}

Bächi, Beat. 2003. Georg Simmel und die Frauen: Macht Körper - Wissen. http://socio.ch/sim/on_simmel/t_baechi.htm. Acesso em 10 jan. 2019.

Bárbara, Lenin Bicudo. 2014. A vida e as formas da sociologia de Simmel. Tempo Social 26 (2): 89-107. DOI: https://doi.org/10.1590/S0103-20702014000200006

Bauman, Zygmunt. 1999. Modernidade e ambivalência. Rio de Janeiro: Zahar.

Benhabib, Seyla e Drucilla Cornell, (orgs.). 1987. Feminismo como crítica da modernidade. Rio de Janeiro: Rosa dos Tempos.

\footnotetext{
8 Em um texto já clássico entre nós, Simmel $(1995,116)$ formulou esse problema da seguinte maneira: "Os problemas mais profundos da vida moderna brotam da pretensão do indivíduo de preservar a autonomia e a peculiaridade de sua existência frente às superioridades da sociedade, da herança histórica, da cultura exterior e da técnica da vida."
} 
Butler, Judith. 2003. Problemas de gênero: feminismo e subversão da identidade. Rio de Janeiro: Civilização Brasileira.

Caillé, Alain. 1988. Nem holismo nem individualismo metodológicos. Marcel Mauss e o paradigma da dádiva. Revista Brasileira de Ciências Sociais 13 (38): 5-37. http://dx.doi.org/10.1590/S0102-69091998000300001.

Chanial, Phillipe. 2004. Além do domínio do interesse? Dádiva, proteção social e renda da cidadania. Caderno CRH: Fevista do Centro de Recursos Humanos da Ufba 17 (40): 17-32. http://dx.doi.org/10.9771/ccrh.v17i40.18478.

Cohn, Gabriel. 1998. As diferenças finas: de Simmel a Luhmann. Revista Brasileira de Ciências Sociais 13 (38): 53-62. http://dx.doi.org/10.1590/S010269091998000300003 .

Coser, Lewis A. 1977. Georg Simmel's neglected contributions to the sociology of women. Signs 2 (4): 869-876. https://doi.org/10.1086/493416.

Elias, Norbert. 1997. Os alemães. Rio de Janeiro: Zahar.

Fraser, Nancy. 2013. Heterosexism, misrecognition and capitalism: a response to Judith Butler. In Fortunes of feminism: from state-managed capitalism to neoliberal crisis, editado por Nancy Fraser, 175-188. Londres: Verso.

Gagnebin, Jeanne Marie. 2011. Cordialidade e estrangeirice: da relação ao outro. Boletim do Museu Paraense Emilio Goeldi. Ciências Humanas 6 (2): 401-408. https:// doi.org/10.15.90/S1981-81222011000200010.

Joseph, Isaac. 2003. Le ressort politique de l'assistance, le moralisme et l'experience de l'induction morale. In Les SDF (sans domicilie fixe). Représentations, trajectoires et politiques publiques, editado por Ministère de l'Équipement, des Transports, du Logement, du Tourisme et de la Mer, 321-345. Paris.

Kracauer, Siegfried. 2004. Georg Simmel: ein Beitrag zur Deutung des geistigen Lebens unserer Zeit (1919). Werke 9 n. 2: 139-280.

Lichtblau, Klaus. 1996. Kulturkrise und Soziologie um die Jahrhundertwende. Zur Genealogie der Kultursoziologie in Deutschland. Frankfurt am Main: Suhrkamp.

Mauss, Marcel. 2017. Ensaio sobre a dádiva: forma e razão da troca nas sociedades arcaicas. In Sociologia e Antropologia, editado por Florência Ferrari, 191-307. São Paulo: Ubu.

Paugam, Serge e Franz Shultheis. 1998. Naissance d'une sociologie de la pauvrété. In Les pauvres, Georg Simmel, 1-34. Paris: Quadrige/PUF.

Pateman, Carole. 1993. O contrato sexual. São Paulo: Paz e Terra.

Schütz, Alfred. 1976. The stranger: an essay in social psychology. In Collected papers II. Studies in social theory, editado por Arvid Brodersen, 91-105.The Netherlands: Martinus Nijhoff.

Scott, Joan. 1995. Gênero: uma categoria útil de análise. Educação \& Realidade 15 (2): 71-99.

Simmel, Georg. 2001. Das Relative und das Absolute im Geschlechter-Problem [1911]. Weibliche Kultur [1911]. In Philosophische Kultur, editado por Georg Simmel, 224-289. Frankfurt: Suhrkamp.
Simmel, Georg. 1995. Die Großstädte und das Geistesleben. In Gesamtausgabe 7. Georg Simmel, 116-131. Frankfurt am Main: Suhrkamp.

Simmel, Georg. 1985. Einiges über die Prostitution in Gegenwart und Zukunft [1892]; Die Rolle des Geldes in den Beziehungen der Geschlechter [1898]; Weibliche Kultur [1902]. In Schriften zur Philosophie und Soziologie der Geschlechter, editado por Heinz-Jürgen Dahme e Klaus Christian Köhnke, 60-71; 139-156; 159-177. Frankfurt am Main: Suhrkamp.

Simmel, Georg. 1999. Grundfragen der Soziologie (Individuum und Gesellschaft) [1917]. In Gesamtausgabe 16, Georg Simmel, 59-149. Frankfurt am Main: Suhrkamp, 1999

Simmel, Georg. 2009. Philosophie des Geldes [1900]. Köln: Anaconda Verlag.

Simmel, Georg. 1992. Soziologie. Untersuchungen über die Formen der Vergesellschaftung [1908]. Frankfurt am Main: Surkhamp.

Stichweh, Rudolf. 2016. Inklusion/Exklusion, funktionale Differenzierung und die Theorie der Weltgesellschaft. In Inklusion und Exklusion. Studien zur Gesellschaftstheorie. Rudolf Stichweh, 47-64. Bielefeld: Transcript.

Vandenberghe, Frédéric. 2018. As Sociologias de Georg Simmel. São Paulo: Edusc.

Varikas, Eleni. 2010. Os refugos do mundo - figuras do pária. Estudos Avançados 24 (69): 31-60. https://doi. org/10.1590/S0103-40142010000200003.

Waizbort, Leopoldo. 2000. As aventuras de Georg Simmel. São Paulo: Editora 34. 2000.

\section{Patrícia da Silva Santos}

Doutora em Sociologia pela Universidade de São Paulo (USP), São Paulo, SP, Brasil. Professora adjunta da Faculdade de Ciências Sociais e do Programa de Pós- graduação em Sociologia e Antropologia (PPGSA) da Universidade Federal do Pará (UFPA), Belém, PA, Brasil. 